\title{
SYMPATHETIC INHIBITION OF THE LARGE INTESTINE IN HIRSCHSPRUNG'S DISEASE ${ }^{1}$
}

\author{
By W. J. MERLE SCOTT AND J. J. MORTON
}

(From the Department of Surgery, University of Rochester, School of Medicine and Dentistry, Rochester, N. Y.)

(Received for publication May 26, 1930)

Physiologists have known for many years that lumbar sympathetic stimulation caused inhibition of motor activity in the colon together with contraction of the internal sphincter ani (1) (2). No direct application of this knowledge to the treatment of Hirschsprung's disease was however attempted until Royle observed marked improvement in the obstinate constipation of spastic paralytic patients after interrupting the lumbar sympathetic connections (3). Hunter studied the problem in the laboratory (4). Their clinical and experimental experiences that improved motor function of an inert colon followed the removal of the sympathetic influence, furnished the basis for testing the effect of a similar procedure in the treatment of congenital idiopathic dilatation of the colon. This condition had long been suspected of having a neurogenic basis (5) (6). But not until the relief of it achieved by Wade and Royle (7) through lumbar sympathetic ramisection, was there any convincing evidence that the extrinsic nervous mechanism of the bowel was etiologically involved.

Besides this original case, the results of interrupting the sympathetic pathways to the colon have been recorded in six others of Hirschsprung's disease. Wade (8) operated upon four of these patients and Judd and Adson (9) reported two. We are sure that some others have been treated in this way but the results are not available as yet in the literature. In five of the seven cases the results have been eminently successful, while in two they have been unsatisfactory. The failure to obtain uniform results raises the question, in a given case of megalocolon what effect will be obtained by operative interruption of its sympathetic innervation. Further information concerning the nature

\footnotetext{
1 Presented before the American Society for Clinical Investigation, May 5, 1930.
} 
and location of the mechanism that seems to be inhibiting normal motor activity in this disease is also desirable. Two typical cases of Hirschsprung's disease recently studied have enabled us to estimate the element of sympathetic overactivity and to trace the site of its origin somewhat further.

\section{CASE REPORTS}

Case 1. V. S. (S. M. H. number 23225), a seven year old Italian boy, entered the hospital on account of extreme constipation. He had never had a bowel movement without the aid of enemas and cathartics. On admission his bowels had not moved for two weeks, a period not unusual for him. During prolonged periods of obstipation his abdomen became prominent, and occasionally he had suffered from nausea and foul vomiting. At the age of thirteen months the mother carried out a series of anal sphincter dilatations under her physician's direction without relief.

Examination showed an alert, somewhat emaciated boy, underdeveloped for his age, with a markedly distended abdomen. Both the sigmoid flexure and the cecum were palpable as non-tender masses. On rectal examination the internal sphincter was spastic. The urine was negative; the hemoglobin was 77 per cent; white blood cells 6,450 ; red blood cells 4,800,000; polymorphonuclears 75 per cent. The Wassermann reaction was negative. The stool was negative. A barium enema on admission (fig. 1) showed an enormous dilation of the rectosigmoid. There was no obstruction.

The clinical diagnosis was a typical example of idiopathic dilatation of the colon (Hirschsprung's disease).

After medical treatment for a month the colon was fairly clean. The significance of the extrinsic nervous mechanism in the clinical picture was then tested in the following manner. A barium enema was given. Four quarts of the solution were injected without causing any discomfort (fig. 2). The patient was then asked to expel as much of the solution as he could, being allowed to sit up for this purpose. By great effort he expelled not over a quart. The width of the colon and the distribution of the barium in it were not materially altered (fig. 3). He was then given spinal anesthesia ( $1 \mathrm{cc}$. of spinocaine used). About five minutes after the introduction of procaine, he began complaining of intense paroxysms of itching in the abdomen. These were soon associated with vigorous peristaltic rushes resulting in involuntary expulsion of the barium. In the next fifteen minutes he was able to expel much of the barium solution, almost completely emptying the right and transverse colons and greatly diminishing the dilatation of the sigmoid flexure (fig. 4). He continued to pass more of the barium voluntarily during the next two hours. Another $x$-ray taken $3 \frac{1}{2}$ hours after the beginning of spinal anesthesia (fig. 5) showed how much he had been able to expel. This great augmentation in the motor efficiency of the bowel, temporarily achieved by paralyzing its extrinsic 
nervous mechanism, seemed to indicate that permanent improvement would follow the removal of the sympathetic impulses to the large bowel. As both the right and left segments of the colon were involved, bilateral lumbar sympathetic ganglionectomy was performed on October 8, 1929. On October 19, he had the first spontaneous bowel movement in his life and by November 1 was having two to four normal soft formed stools per day. On November 4 , another barium enema was

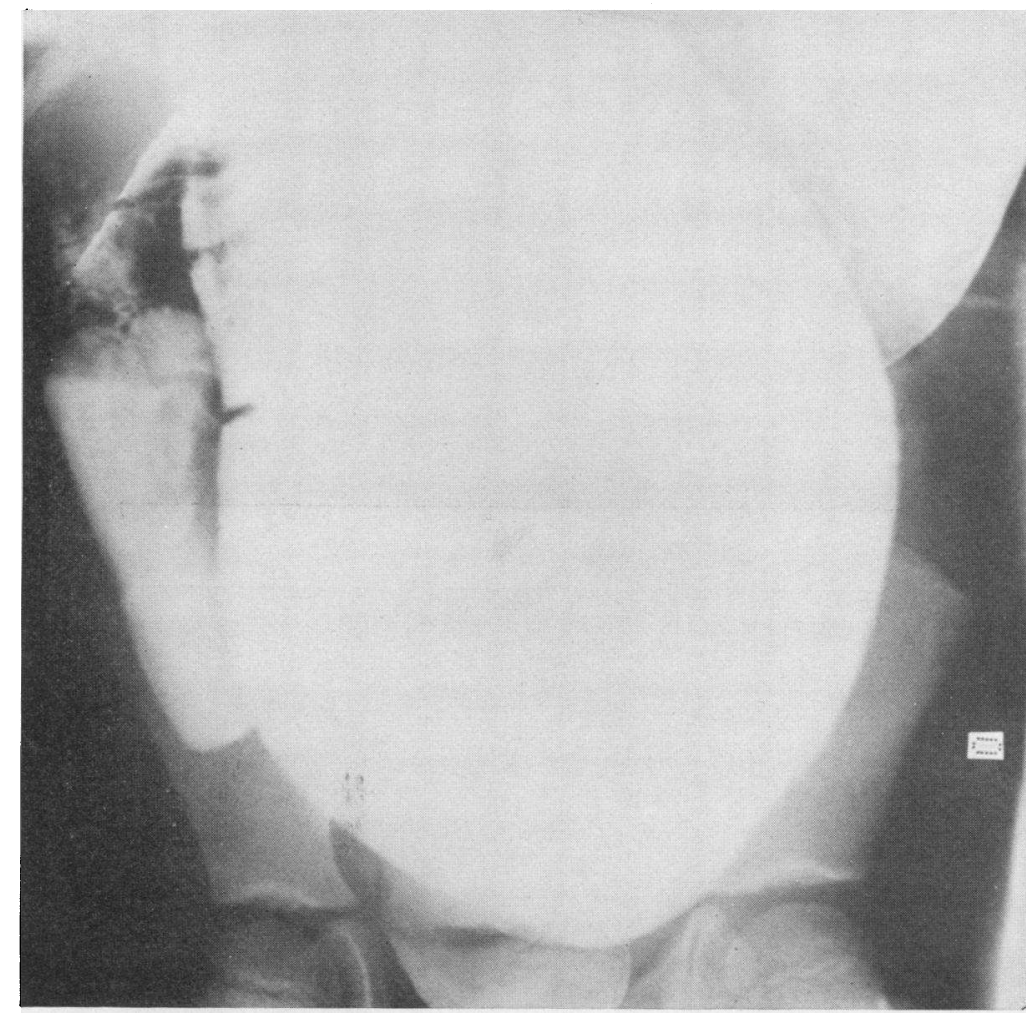

Fig. 1. Case 1. Megalocolon on Admission

given to record the motor power of the colon. In the first place about two and a half quarts now produced a sensation of fullness so that he had some difficulty in retaining the enema (fig. 6). When allowed to expel it he evacuated about half of the mixture, almost completely emptying the right colon (fig. 7). Three hours later the striking haustration of the bowel was in evidence (fig. 8). He was discharged from the hospital on November 9, 1929.

January 10, 1930, another barium enema was given which he now had even greater difficulty in retaining. When two quarts had been injected he had a feel- 

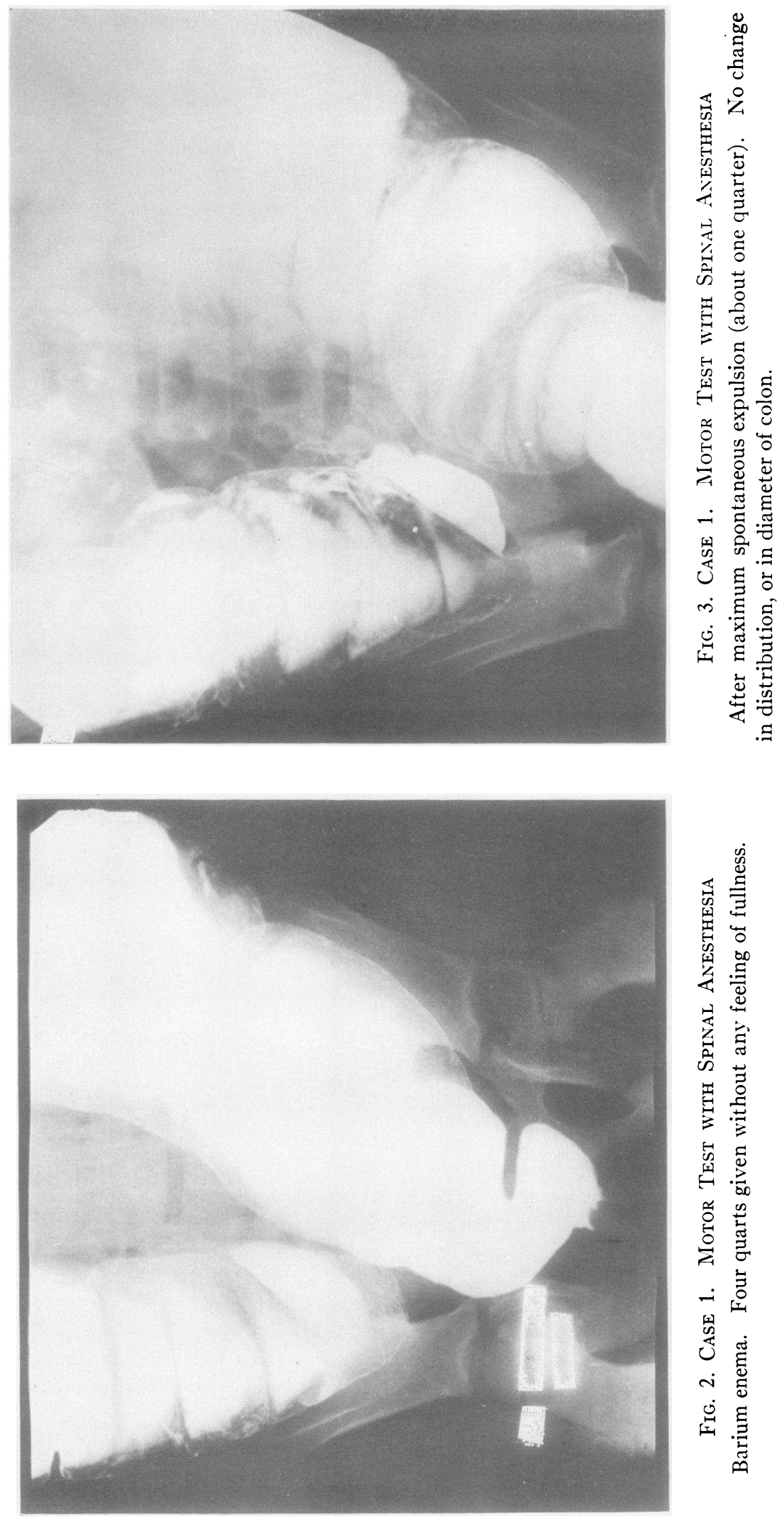

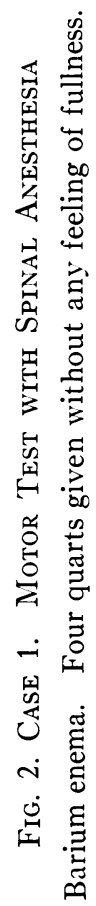



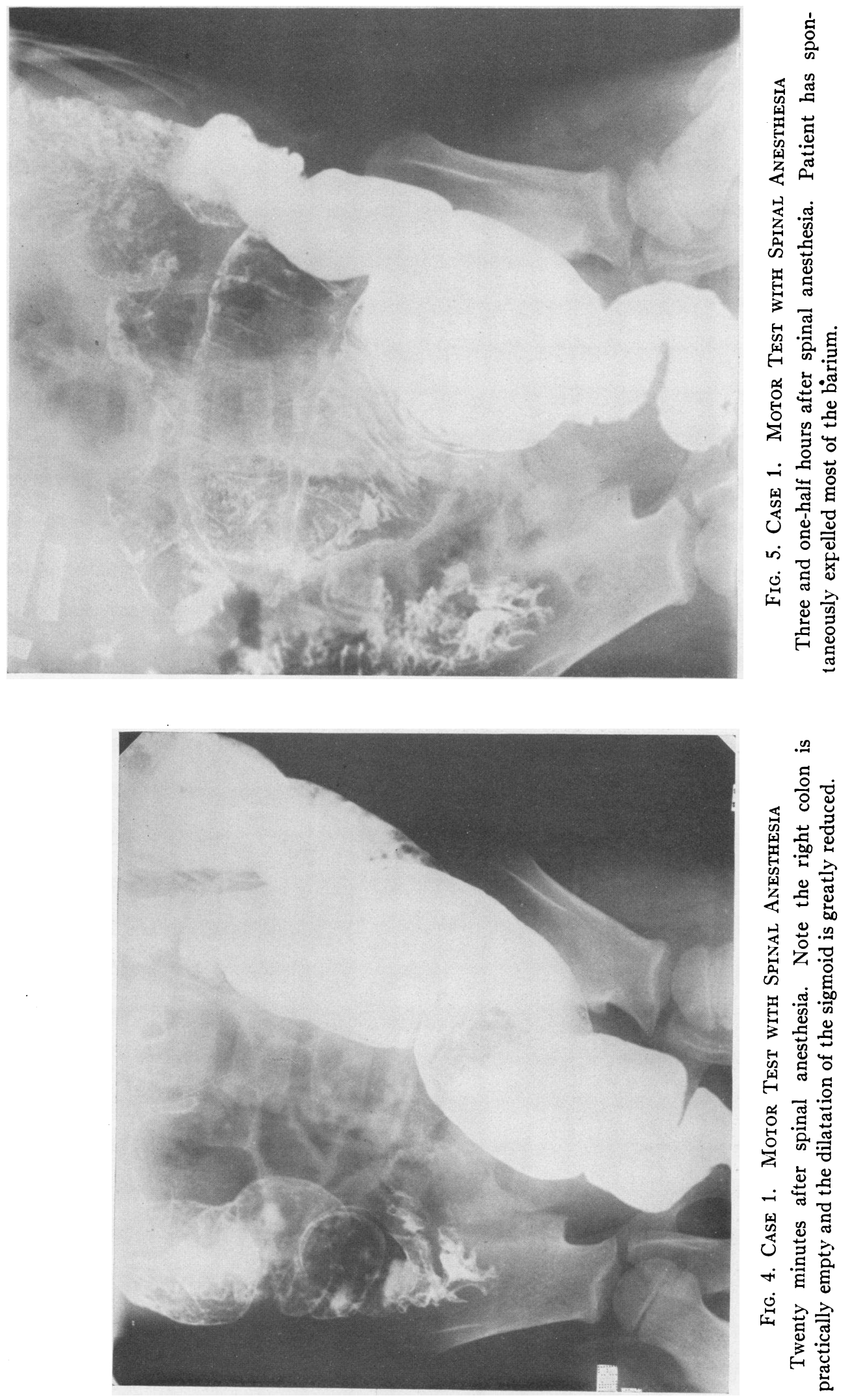

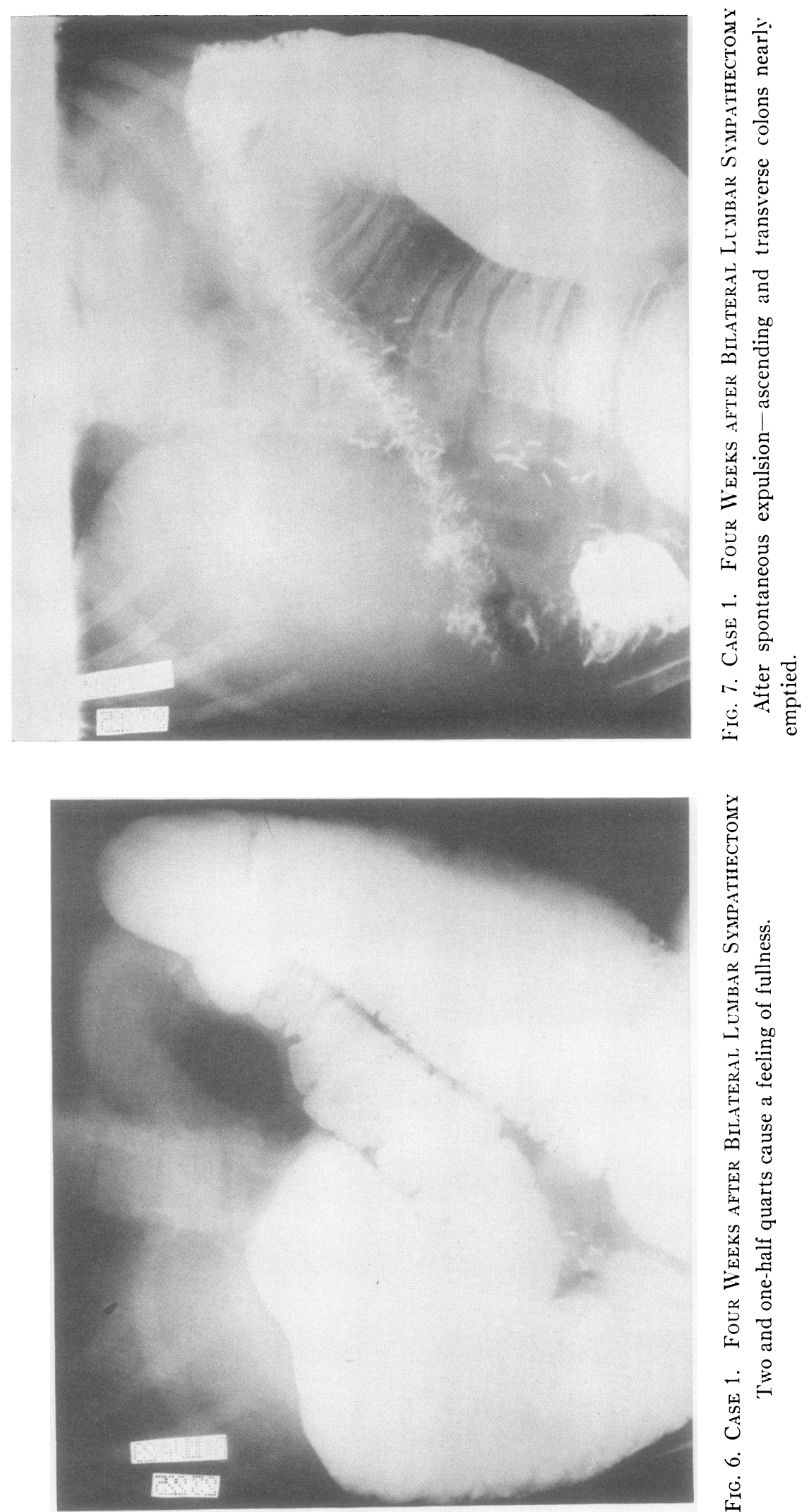
ing of great fullness (fig. 9). When allowed to evacuate the enema he expelled every trace of barium (fig. 10).

Since November 1, 1929 (three weeks after operation) to the present (six months) he has been having regular daily spontaneous bowel movements usually twice a day, and has gained five pounds in weight since his operation.

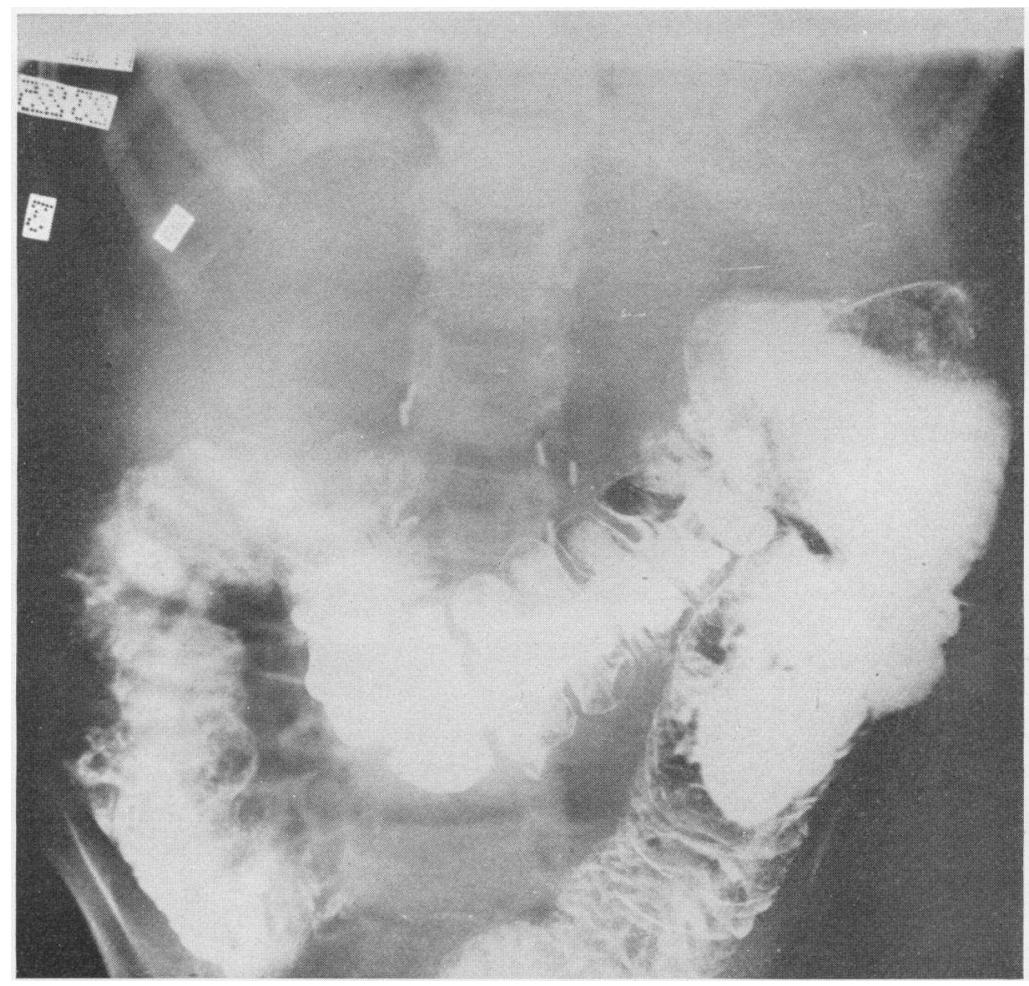

Fig. 8. Case 1. Four Weeks after Bilateral Lumbar Sympathectomy

Four hours later. Spontaneous evacuation has expelled most of the enema. Note the excellent haustration in transverse colon.

Case 2. R. L. (S. M. H. number 32554), a five year old boy, had been constipated since birth. In the first two weeks of his life only one bowel movement was obtained. His local physician, thinking that the sphincter might be tight, instructed the mother to dilate it every day. This maneuver did not, however, result in better evacuations. He has since then only twice had a desire to defecate and has not had a bowel movement without the aid of cathartics and enemas. His mother by constant attention, by giving large doses of cathartics and frequent 

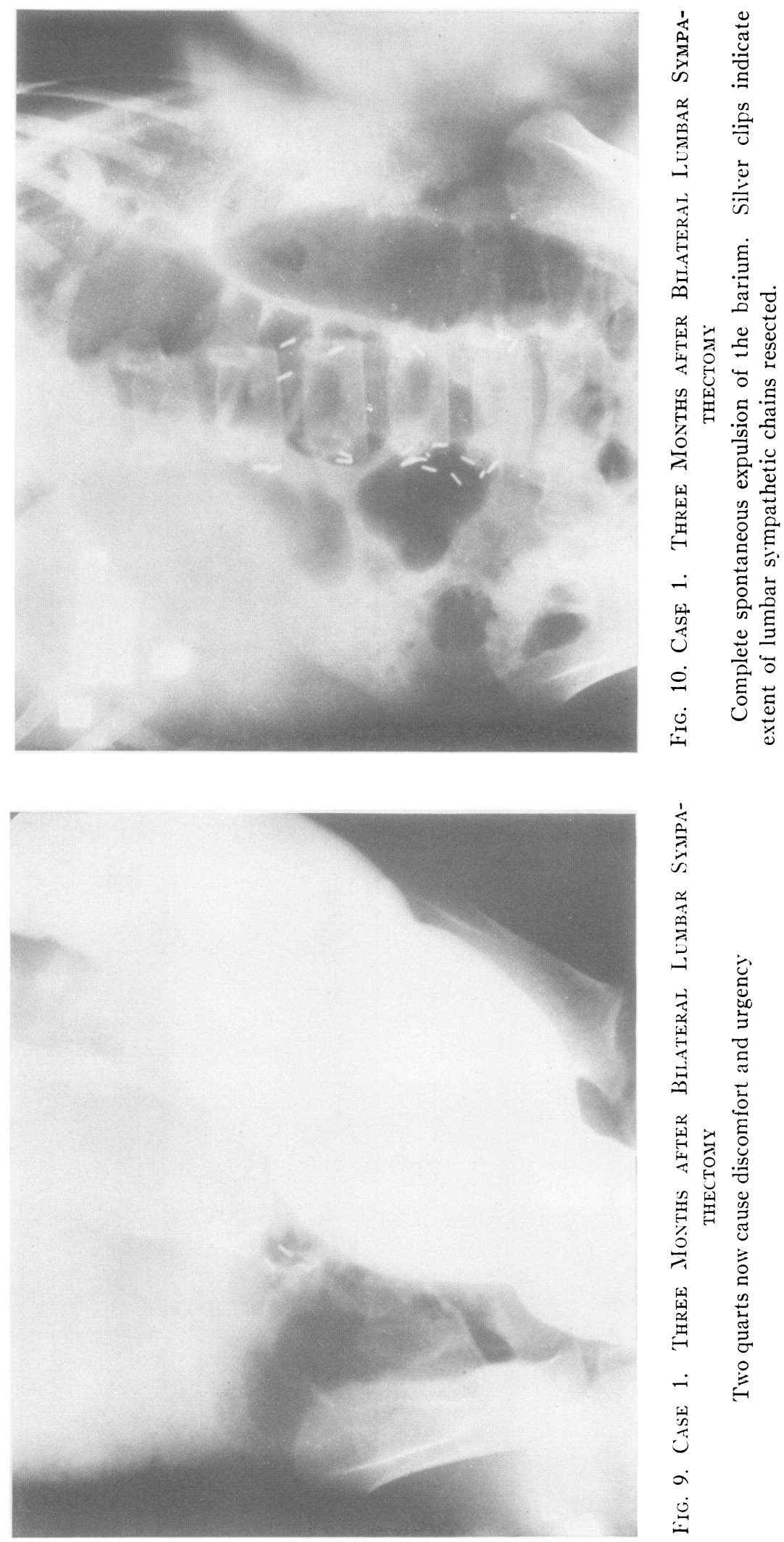

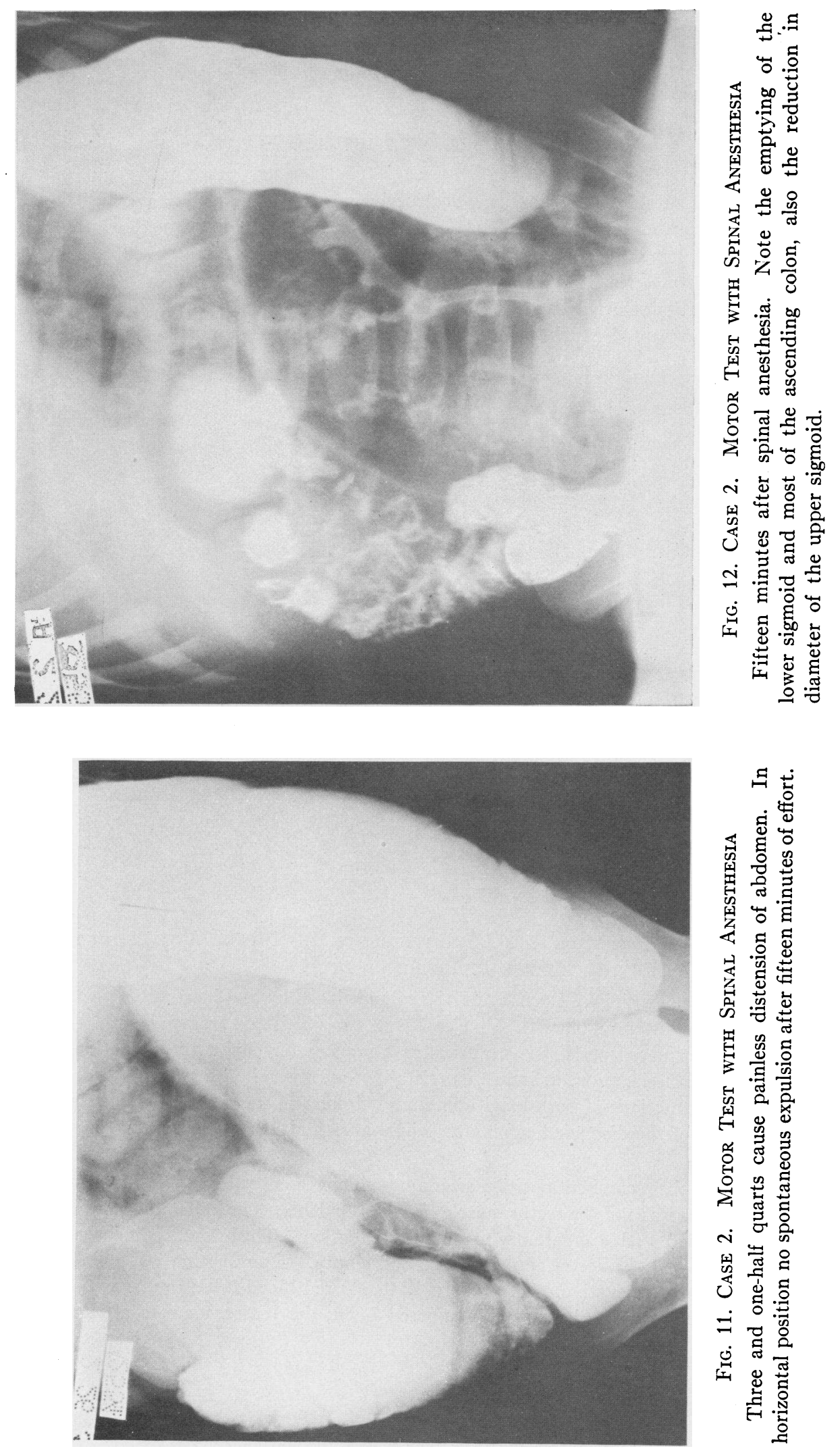
enemas has succeeded in preventing obstructive vomiting. Nine days frequently passed nevertheless without a bowel movement. His appetite would become poor, his abdomen greatly distended. When his bowels moved he passed enormous amounts of material.

Examination showed an alert, well-developed youngster. His mucous membranes appeared to be slightly pale. When he stood erect his aldomen was promi-
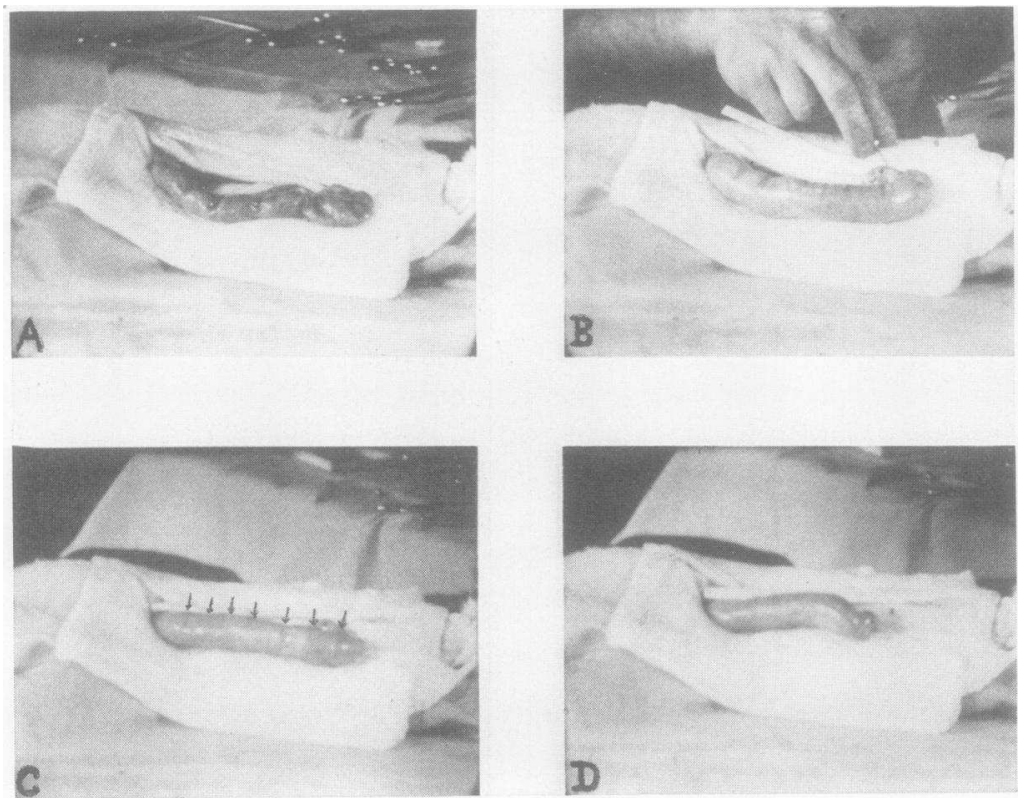

Fig. 13. The Effect of Spinal Anesthesia on the Motor Activity in the Large Intestine of the Cat

A. After exposing and walling off the colon it is flabby and inert.

B. Even distending it with saline causes no peristalsis and no emptying.

C. Coördinated peristalsis begins almost immediately upon the induction of spinal anesthesia. Arrows indicate peristaltic waves seen in the moving film.

D. Contractions of both longitudinal and circular fibers cause shortening and emptying of the distended colon after spinal anesthesia.

nent. In the recumbent position after a bowel movement, when his abdomen was relaxed, diastasis of the rectus muscles became evident. The abdominal wall was thin and flabby, due apparently to periodic distension. The internal sphincter ani was tight and the rectal ampulla large and empty. Examination was painless. The urine was negative. There were 4,540,000 red blood cells; the hemoglobin was 75 per cent; the leucocytes numbered 7,850 ; the Wassermann reaction was negative. 
His markedly dilated colon held three and a half quarts of barium solution (fig. 11). The abdomen became very prominent but he experienced no discomfort. After fifteen minutes of effort he was unable in the horizontal position to expel any. Spinocaine, $0.8 \mathrm{cc}$. diluted during injection with spinal fluid to $2.2 \mathrm{cc}$. was injected intraspinally. In about twelve minutes he became anesthetic to the level of the umbilicus and hypoesthetic well above the costal margin. He had also lost the ability to move his toes. He complained of itching of the abdomen and scratched vigorously. When the sensory and motor symptoms first began to appear he became nauseated and simultaneously evacuated a large quantity of the barium enema. At the same time he vomited a small amount. After several evacuations of rectal contents his abdomen became relaxed. Fifteen minutes after the beginning of the spinal anesthesia another $x$-ray was taken which showed that most of the barium enema had been expelled. The ascending and transverse colons were nearly empty. The sigmoid flexure still contained a moderate amount but its diameter was greatly reduced (fig. 12).

The results of this test convinced us that sympathetic overactivity played the predominant rôle in this boy's disease and that interrupting sympathetic impulses would result in permanent improvement. He has not yet been operated upon.

In these two typical cases of Hirschsprung's disease spinal anesthesia temporarily terminated the motor inertia of the large bowel. In order to test the efficiency of this procedure experiments were carried out in animals. The colon was exposed in ten cats by opening the abdomen under light ether anesthesia. The small intestine was packed off with gauze. The surface of the colon was kept moist by a saline spray. Under these conditions the colon was always found to be inert. If its wall was stimulated by pinching, a small local contraction occurred. Coordinated peristalsis of the large intestine was observed in only one of the ten cats. In this animal (a pregnant cat) on first opening the abdomen a few feeble, ineffective peristaltic waves were seen, but they ceased entirely within three minutes. Distending the colon with saline solution through the ileocolonic valve in no case caused any peristalsis or evacuation of its contents. Profound asphyxia was the only state in which motor activity took place when the extrinsic innervation remained intact.

If however, the paths of the sympathetic nerves to the large bowel were interrupted at any point, vigorous motor activity promptly appeared. If both lumbar sympathetic chains or the inferior mesenteric ganglia were removed, then peristalsis and increased muscular tonus was widespread. But, if one or more of the colonic nerves in 
the mesentery of the colon were cut distally to the inferior mesenteric ganglion, then motor activity appeared only in the segment supplied by that nerve. Evidently there is constant sympathetic stimulation passing to the colon under the conditions of the experiment (probably a reflex from the peritoneal wound) completely inhibiting motor activity until the sympathetic pathway is interrupted. Spinal anesthesia was followed in every instance by the onset of motor activity fully as marked as followed complete mechanical interruption of the sympathetic fibers to the colon. A small area of the dura was exposed in the lower lumbar region. Through a fine 27 gauge right angled needle as much spinal fluid was aspirated as possible. Ten per cent procaine (usually in the form of spinocaine, Metz) was injected into the subarachnoid space, the foot of the table being elevated five degrees. Vigorous peristalsis and anti-peristalsis began in the colon, usually within five minutes, followed very quickly by shortening and narrowing of the whole large bowel. If the colon had been distended with fluid before the induction of spinal anesthesia, motor activity brought about evacuation of its contents. A motion picture film shows this sequence of events. The four stages of this process are shown in figure 13 , taken from this film. If the attempt was made during spinal anesthesia to inject fluid into the colon it could not be distended as it could easily have been before paralyzing the sympathetic innervation. At about the time that motor activity appeared in the colon it was found that the muscular tonus of the lower extremities was lost while that of the upper extremities was unaffected. In other words, procaine had resulted in paralysis of the lumbar motor nerves to striated muscles and of the sympathetic inhibitory nerves to the large intestine. We conclude from these experiments that spinal anesthesia is a satisfactory method of overcoming temporarily sympathetic inhibition of the colon.

\section{DISCUSSION}

Spinal anesthesia as a test of sympathetic overactivity. Pioneer efforts have opened up great possibilities in several different fields for the removal of an excessive sympathetic stimulation. The greatest need in this development appears to be accurate criteria to demonstrate whether sympathetic overactivity is present and, if so, what will be 
the effect of its removal. For this purpose temporary abolition of sympathetic stimulation seems a priori the most reasonable procedure, and in practice has given us excellent results in the gastro-intestinal and the vascular systems.

In the two clinical cases of Hirschsprung's disease we have demonstrated the immediate augmentation in motor activity of the large bowel upon the induction of spinal anesthesia. ${ }^{2}$ In one of these cases it has been further shown that such temporary improvement in function has been made continuous by the removal of the lumbar sympathetic chains. The animal experiments have shown that spinal anesthesia is entirely effective in overcoming sympathetic inhibition of the colon. We propose the adoption of this procedure to ascertain in any individual case of megalocolon how effective operative interruption of its sympathetic innervation will prove to be.

The nervous mechanism involved. These observations have advanced somewhat farther our knowledge of the mechanism underlying the motor anomaly of Hirschsprung's disease. The previous results of operations on the sympathetic nervous system (Wade and Royle (7), and Judd and Adson (9)) have made it clear that there is probably sympathetic overactivity in this condition. But both types of operation employed by them, ramisection and ganglionectomy, trace the origin of the sympathetic influence with certainty only to the lumbar ganglia and do not establish involvement of the central nervous system, although both reports quoted express the opinion that the latter is implicated. The effectiveness of spinal anesthesia makes clear, however, that motor inactivity in at least one type of Hirschsprung's disease is dependent upon central sympathetic inhibition of the large bowel. Whether sympathetic stimuli to the colon arise from impulses originating in the cord at higher levels or reflexly from sensory stimuli in the splanchnic area cannot be decided upon the basis of our present information. Experimentally in animals both types of sympathetic inhibition of the colon have been demonstrated; from higher centers by Hunter (4), and in the case of the peritoneal cavity by our experiments. The information at our disposal does not even permit the inference that the actual number or strength of sympathetic efferent

\footnotetext{
${ }^{2}$ In choosing the dosage in children of various ages we have followed the table worked out by Pitkin (16).
} 
impulses in this disease is greater than normal, since it would be possible to account for the known facts on the basis of peripheral hypersensitivity to normally acting, constant sympathetic stimulation. This explanation seems however less likely. In any event, the effectiveness of spinal anesthesia in permitting motor activity of the bowel affords strong evidence for the belief that the anomaly in our cases of Hirschsprung's disease is not due to permanent injury to or defect in the neuro-muscular mechanism such as degeneration in Auerbach's plexus as described by Cameron (10). It also shows that efferent stimuli initiated in the central nervous system and traveling over the lumbar sympathetic pathways to the large bowel play a leading rôle in the mechanism. Whether the sympathetic influence is chiefly exerted through the inhibition of the muscular coats of the colon or through contraction of the sphincters (internal sphincter ani and O'Beirne's) is another point that we have no way of deciding at present. Sympathetic stimulation brings about both of these results, (Bayliss and Starling, (2) and Learmonth and Markowitz (11)) and probably both of them play a certain part. The peristaltic rushes observed under spinal anesthesia suggest that the activity of the intrinsic musculature was at least as important as the relaxation of sphincters.

Results of sympathectomy. As eminent an authority on the surgery of the autonomic nervous system as Kappis (12) stated in 1929, "Tierny ${ }^{3}$ made the proposal to divide the rami communicantes of $\mathrm{L} 1$ and $L 2$ in megalocolon and so to decrease the spastic tonus; he will probably not find many imitators." In view of the small number of cases of Hirschsprung's disease so far treated by sympathetic operations it may be well to call attention to the extremely promising results that have been achieved. Our case adds another to this small group. When he came to us, this seven year old boy had never had a spontaneous bowel movement without the aid of strong catharsis and enemas. Since operation (six months) he has continuously had normal daily evacuations without assistance. .

The operation of choice at the present time we believe is lumbar sympathetic ganglionectomy as devised by Adson (15). Eventually

${ }^{3}$ Tierny (13) reviewed an article by Bartle (14) who in 1926, on the basis of Royle and Hunter's observations, advised sympathetic ramisection for Hirschsprung's disease before any of the results of this procedure had been reported. 
it will probably be feasible to interrupt the nervous pathways to the colon in the region of the inferior mesenteric ganglion, without interfering with other pathways in the lumbar sympathetic outflow. At present, assurance of complete interruption of stimuli to the large bowel is more important than preserving the sympathetic innervation of the extremities. If this test is used to select appropriate cases and if an operation certain to permanently interrupt the entire sympathetic innervation of the large bowel is chosen we feel confident that the results of the latter will be most satisfactory.

\section{CONCLUSIONS}

1. At present a most important desideratum in surgery of the sympathetic nervous system is the development of accurate criteria for detecting sympathetic overactivity in the various systems affected.

2. The temporary interruption of sympathetic stimuli to the involved area is used to select appropriate cases and to estimate how much effect removal of sympathetic innervation will have.

3. Spinal anesthesia has produced temporarily motor activity of the colon in two cases of Hirschsprung's disease and in experiments in animals.

4. The motor anomaly in at least one type of megalocolon is dependent upon central sympathetic inhibition of the large bowel.

5. We propose the effect of spinal anesthesia upon the motor function of the large bowel as a test of sympathetic overactivity in Hirschsprung's disease.

\section{BIBLIOGRAPHY}

1. Langley, J. N. and Anderson, H. K., J. Physiol., 1895, xviii, 67. On the Innervation of the Pelvic and Adjoining Viscera. Part. I. The Lower Portion of the Intestine.

2. Bayliss, W. M. and Starling, E. H., J. Physiol., 1900-1901, xxvi, 107. The Movements and the Innervation of the Large Intestine.

3. Royle, N. D., M. J. Australia, 1924, xi, 77. A New Operative Procedure in the Treatment of Spastic Paralysis and its Experimental Basis.

4. Hunter, J. I., M. J. Australia, 1924, xi, 86. The Postural Influence of the Sympathetic Innervation of Voluntary Muscle.

5. Finney, J. M. T., Surg. Gynec. and Obst., 1908, vi, 624. Congenital Idiopathic Dilatation of the Colon. 
6. Hawkins, H. P., Brit. M. J. 1907, i, 477. Remarks on Idiopathic Dilatation of the Colon.

7. Wade, R. B., and Royle, N. D., M. J. Australia, 1927, xiv, 137. The Operative Treatment of Hirschsprung's Disease; A New Method.

8. Personal Communication from Dr. R. B. Wade to Dr. W. C. Alvarez quoted by Judd and Adson.

9. Judd, E. S., and Adson, A. W., Ann. Surg., 1928, lxxxviii, 479. Lumbar Sympathetic Ganglionectomy and Ramisection for Congenital Idiopathic Dilatation of the Colon.

10. Cameron, J. A. M., Arch. Dis. Childhood, 1928, iii, 210. On the Etiology of Hirschsprung's Disease.

11. Learmonth, J. R., and Markowitz, J., Am. J. Physiol., 1929, lxxxix, 686. Studies on the Function of the Lumbar Sympathetic Outflow. I. The Relation of the Lumbar Sympathetic Outflow to the Sphincter Ani, Internus.

12. Kappis, M., Beitr. z. Klin. Chir., 1929, cxlvii, 343. Die Ergebnisse der Chirurgie des vegetativen Nervensystems nach eigenen und fremden Erfahrungen.

13. Tierny, A., Gaz. d. hôp., 1928, ci, 228 Méga-colon-Son Traitement par la sympathicectomie.

14. Bartle, H. J., Am. J. Med. Sci., 1926, clxxi, 67. Megacolon-A Résumé of the Literature and Report of a Case: Ramisection Proposed as a Form of Treatment.

15. Adson, A. W., Surg. Clin. N. Am., 1925, v, 777. Ramisection for Spastic Paralysis.

16. Pitkin, G. P., Brit. Med. J., 1929, ii, 183. Spinocain: The Controllable Spinal Anaesthetic. 